\title{
Sustainability transitions: insights on processes of niche-regime interaction and regime reconfiguration in agri-food systems
}

\author{
S. Bui (a) ${ }^{1}$, A. Cardona (a), C. Lamine (a), M. Cerf (b)
}

\begin{abstract}
a: INRA Ecodéveloppement, 228 route de l'aérodrome. CS 40509. Domaine St Paul - Site Agroparc. 84914 Avignon, France; sibylle.bui@uclouvain.be; $\underline{\text { acardona@paca.inra.fr; }}$ clamine@ paca.inra.fr

b: Université Paris-Est Marne-la-Vallée, Cité Descartes, 5 boulevard Descartes, Champs-sur-Marne, 77454 Marne-la-Vallée Cedex 02, France; cerf@agroparistech.fr)
\end{abstract}

Article published in Journal of Rural Studies 48:92-103, December 2016.

DOI: 10.1016/j.jrurstud.2016.10.003

\begin{abstract}
Changing farming practices is a major issue for sustainability. Such change is difficult to bring about because of strong lock-in effects within the agri-food system. Scholars have mobilized diverse approaches to address the issue of changes in agriculture, including the multi-level perspective (MLP). However, the mechanisms through which "niches" can contribute to regime reconfiguration are still unclear. In this article, we combine the diachronic and systemic approach from the MLP with insights from French pragmatic sociology and from the Alternative Food Networks literature. We analyse the trajectories of four initiatives, which can be considered as niches, as they associate various actors and develop radical innovations. Comparing their trajectories allows us to identify a generic pattern in niche development and niche-regime interactions. We identify regime reconfiguration mechanisms common to all four case studies. Niche activities and the
\end{abstract}

\footnotetext{
${ }^{1}$ Corresponding author. Present address: Université Catholique de Louvain-la-Neuve, Centre for Philosophy of Law (CPDR), SSH/JURI/PJTD - L2.07.01, Collège Thomas More, place Montesquieu 2 (box 15), B-1348

Louvain-la-Neuve, Belgium
} 
enrolment of new actors lead to a gradual reconfiguration of the regime: first, through the construction of shared visions of agri-food issues and of the associated network of relevant actors; second, through their embedding in local policies and public action.

Keywords: sustainability transitions; multilevel perspective; niche-regime interactions; agrifood system; alternative food networks

\section{Highlights}

- In an analysis of 4 niches, we identify a single pattern of niche-regime interaction

- New visions of agri-food issues and their governance are developed inside the niches

- Niche actors perform their embedding in the regime through enrolment processes

- This induces some regime reconfiguration that we assess at the local scale

- Redefining the network of relevant actors is crucial for regime reconfiguration to occur 


\section{Introduction}

Conventional farming ${ }^{2}$ as a dominant model is increasingly being challenged. Laws on water or pesticide use and policies to encourage more sustainable farming systems have been gradually implemented in response to criticism. In 2008, for example, the French Ministry of Agriculture released the action plan Ecophyto 2018, aiming for a 50\% reduction in pesticide use by 2018 "if possible", and in 2009 the EU Parliament adopted the "Pesticide package" which requires all Member States to set up action plans to encourage the widespread adoption of technical alternatives to the use of pesticides. However, these measures have only had marginal effects and seem unable to trigger deep change in French and European agriculture. Previous studies have revealed how agriculture is trapped in a lock-in situation, as the whole sociotechnical system is organized around high-input farming systems (e.g. Cowan and Gunby, 1996; Stassart and Jamar, 2009; Vanloqueren and Baret, 2008). This explains why changes in farming practices are contingent on a profound reconfiguration of the whole agrifood system, i.e. change in the practices and modes of coordination of all incumbent actors farmers, processors, distributors, consumers, public policies, research and extension services (Lamine et al., 2012).

At the same time, diverse types of alternative food networks (AFN) are being implemented by multi-actor networks that have received a lot of attention from scholars. These networks are spaces where local actors develop new modes of coordination to contribute to reconnecting consumers and producers and challenge some of the characteristics of the conventional food

\footnotetext{
${ }^{2}$ I.e. farming systems dependent on chemical pesticides and fertilizers.
} 
and farming regime ${ }^{3}$ (Deverre and Lamine, 2010). As such, they generate bottom-up solutions to break down some of the barriers limiting the adoption of alternative farming practices and show some potential to overcome the lock-in effects involved in the conventional regime. Previous studies on alternative food networks have explored their transformative potential (for a review, see Tregear, 2011; Goodman et al., 2011). Some authors have analysed their repertoires of arguments and action, such as consumer education, the implementation of alternative forms of trade and consumer mobilization for protest campaigns. They have highlighted the difficulties faced by these organizations to articulate political action and economic commitment (Dubuisson-Quellier et al., 2011). Others have analysed how in some alternative food networks, values gradually become anchored in everyday practices: through membership in a GAS (Italian for Solidarity-based Purchase Groups), consumers are changing their attitude and adapting their purchasing and consumption routines (Brunori et al., 2012). However, the way such initiatives can shake up the conventional regime is still an open research question (Deverre and Lamine, 2010; Goodman et al., 2011). Moreover, since change in farming practices depends not only on the way supply chains are organized but also, more broadly, on the functioning of the whole agri-food system, more diverse alternative networks - not only those focused on food issues - may be necessary for a regime reconfiguration to take place.

In this paper, we analyse the processes through which alternative networks can contribute to such a regime reconfiguration. To do so, we combine alternative food network approaches with a multi-level perspective (Geels, 2002), which we articulate with some input from French pragmatic sociology.

\footnotetext{
${ }^{3}$ Which is based on farming systems dependent on pesticide use, standardized food and long-distance trade.
} 
The multi-level perspective (MLP) is a heuristic framework used to analyse transitions defined as processes of profound regime reconfiguration resulting in a shift from one sociotechnical system (in our case, the conventional agri-food system) to another. It distinguishes between three analytical levels: the niche level where radical innovations and associated sociotechnical practices and rules are developed; the regime level where established practices and rules stabilise existing sociotechnical systems (i.e. the conventional agri-food system in our case); and the landscape level, which represents the exogenous economic, political and cultural context beyond the influence of niche and regime actors (Rip and Kemp, 1998; Geels, 2002, 2011).

Niches are spaces where small networks of actors develop radical innovations on the margins of the regime (Geels and Schot, 2007). The concept of niche is very congruent with the definition of alternative food networks, except that it is not restricted to food networks. In fact, the concept of niche originates from evolutionary economics which analyses technological evolution. It is therefore primarily interested in the fact that alternative networks support new technology: in the MLP, niches are "breeding spaces" protected from market selection (Kemp et al., 1998) where learning processes allow actors to develop new rules and practices around new technology. They are therefore innovative sociotechnical configurations and are considered as the seeds for systemic regime change (Wiskerke and Van der Ploeg, 2004; Geels, 2011). In this paper, we will consider that niches are initiatives in which new rules and practices (i.e. rules and practices representing a breakthrough in relation to the rules in force and the practices carried out in the conventional regime) are developed by a network of diverse actors of the agri-food system.

Niche development is necessary but not sufficient to trigger a regime shift (Berkhout et al., 2011). Niche-regime interaction is another key process in transitions, as through this particular process new rules and practices are integrated within the regime, bringing about 
further, more profound regime reconfiguration. Although this process is identified by the MLP authors as crucial in transition dynamics, a "theory of linking" is still lacking (Smith, 2007). In other words, the way social actors can gain a grip on sociotechnical developments is still a weak area of the sustainability transition literature (Genus and Coles, 2008). Elzen et al. (2012) have analysed the constituent elements of the regime through which niche-regime linking may occur, and have identified three forms of "anchoring" (technological, network and institutional) to characterize the nature of this interaction. However, the mechanisms whereby these links are built and whereby they contribute to a regime reconfiguration remain a blind spot that we wish to shed light on in this article.

In order to do so, we combine a pragmatist approach with the diachronic and systemic focus of the MLP - which Diaz et al. (2013) have proven to be fruitful to understand the dynamics involved in building links. The pragmatist approach allows focusing on enrolment processes contributing to the creation of new interactions, on the breaking of alliances, and on the alignment of the actors' interests, concerns and visions (Callon, 1981; Callon and Law, 1982). As we will demonstrate, this allows us to describe precisely both the mechanisms of nicheregime linking, and the mechanisms of change at the regime level.

In this article we analyse four case studies corresponding to different types of niches (not only alternative food networks). As transitions can only be assessed retrospectively, our aim is not to ascertain whether these niches trigger a sociotechnical transition as defined by the MLP (i.e. a profound regime reconfiguration); it is to provide a better understanding of nicheregime interactions by analysing the mechanisms of link construction and how they lead to some regime reconfiguration. In order to analyse niche-regime interactions, we offer a parallel study of these niches' trajectories over time and of their impact on the agri-food regime through the lenses of pragmatist sociology. We analyse the reconfiguration of the actions and visions of both niche and regime actors. We analyse this at a local level, and consider that a 
regime reconfiguration is occurring if the actions and visions of regime actors become aligned with those built by niche actors.

This article is organized in three sections. In the next section, we present the four case studies and the method used to analyse how these niches unfolded. In Section 3, we describe the four niches' trajectories and suggest a generic pattern that such trajectories follow, in order to better understand the interactions between niches and the regime. In Section 4, we characterize the mechanisms that enable regime reconfiguration through these interactions.

\section{Presentation of the case studies}

Our analysis is based on the comparison of four case studies: a community procurement platform, a farm incubator, an $\mathrm{AMAP}^{4}$ and a community organization mobilized for the preservation of water quality. As will be shown in section 3, these initiatives gradually enrolled diverse actors of the agri-food system and lead to the construction of rules and practices that differ radically from those of the conventional regime: in other words, they offer four cases of "niches". We chose these initiatives because they are cases of "niches" acting on different components of the local agri-food system (here, particularly supply chains, land access and farming practices). We also deliberately chose cases from different contexts (demographics, institutional dynamics and farming activity) in order to obtain some generalisability.

\footnotetext{
${ }^{4}$ Association pour le Maintien de l'Agriculture Paysanne (AMAP). AMAPs are Community Supported Agriculture (CSA) initiatives where consumers enter into medium-term contracts (often six months) with one or more producers who undertake to supply them with a weekly box of fresh organic farm produce.
} 
The two first cases are located in the Drôme valley, a mountainous rural area in Southeast France, located between the Alp foothills and the Rhône valley. Due to the diversity of farming systems involved (field crops, seeds, fruits, garlic, goat, sheep, aromatic and medicinal plants, vegetables and wine are locally farmed), there is little intensive use of chemical inputs in farming in the area. Organic farming accounts for $30 \%$ of cultivated areas. In this territory ${ }^{5}$, agricultural development is central to the broader issue of rural development. Between 2009 and 2014, the four communities of municipalities in the valley carried out a public policy programme named "Biovallée", to make the Drôme valley a reference territory for sustainable development. Farming was a key strategic domain in this programme, and the objectives were to reach a $50 \%$ rate of organic farmers, an $80 \%$ rate of local and/or organic products in local catering and a 50\% reduction of pesticide use. This programme's initial strategy was to foster the development of a local agro-industrial cluster specialized in organic products, in order to encourage farmers to convert to organic farming and to keep the added value within the territory. As we will see, this strategy has been influenced strongly by the initiatives we studied.

The two other case studies are located in two distinct territories of the Paris basin, a region comprised of a patchwork of urban areas and cereal plains mainly cultivated with conventional practices - only $1.6 \%$ of the utilized agricultural area is organically farmed. One of these two territories is located in a rural area (about $80 \mathrm{~km}$ east of Paris) dedicated to cereal farming, an industry in which the issue of farming practices' impact on water quality emerged in the early 1990s and gradually made its way onto local agricultural and public actors' agendas, within the context of more constraining European and national water regulations.

\footnotetext{
${ }^{5}$ In this paper, we use the word 'territory' in relation with three meanings: a locality (i.e. a small region), a geographical area associated with a cultural identity and/or a perimeter of action. Presently, in the case of the Drôme valley, it encompasses all three meanings.
} 
The other territory is the Saclay Plateau, about $30 \mathrm{~km}$ south of Paris. Urbanization in this territory started in the early $20^{\text {th }}$ century and few farmers survived this urban sprawl. Today, there are only eight farmers still cultivating land in the community of municipalities of the Saclay Plateau. Only two of them are organic farmers and their organically farmed utilized agricultural area represents around 5\% of the total agricultural area of the plateau $(3,000$ hectares in 2000). While the preservation of farmland was not initially a priority for public decision makers, it became more and more important in recent years as the urban sprawl began to threaten the last farmers of the plateau and discontent grew among non-farming inhabitants.

The Drôme valley is an area where inhabitants share quite a strong history and local culture, but also a strong attachment to their territory, whether they come from long-established local families or they chose to move here. Most of their everyday practices are also linked to the territory and take place there, partly because it constitutes a geographical enclave (a valley surrounded by quite high mountains). In contrast, in the two areas in the Paris region, the cultural identity seems less pronounced, mobility is often higher, and everyday practices often spread well beyond the territory, due to a much higher permeability with nearby areas in a flat and very urban region.

Table 1 summarizes the characteristics of our case studies and their regions.

\begin{tabular}{|l|l|l|l|l|}
\hline Case study & Agricourt & Compagnons & AMAP Ceres & Aqui'Brie \\
& & de la Terre & & \\
\hline Initiators of & Civil society & Civil society & Civil society & Department \\
\hline
\end{tabular}




\begin{tabular}{|c|c|c|c|c|}
\hline the initiative & & & & $\begin{array}{l}\text { council and } \\
\text { civil society }\end{array}$ \\
\hline $\begin{array}{l}\text { Other actors } \\
\text { involved }\end{array}$ & $\begin{array}{l}\text { Producers, } \\
\text { artisanal food } \\
\text { processors, } \\
\text { distributors, } \\
\text { local } \\
\text { authorities }\end{array}$ & $\begin{array}{l}\text { Producers, local } \\
\text { authorities }\end{array}$ & $\begin{array}{l}\text { Producers, local } \\
\text { representatives, } \\
\text { municipalities, } \\
\text { managers of } \\
\text { canteens }\end{array}$ & $\begin{array}{l}\text { Producers, } \\
\text { local } \\
\text { authorities, } \\
\text { agriculture } \\
\text { Chamber of } \\
\text { agriculture }\end{array}$ \\
\hline Objectives & $\begin{array}{l}\text { Creation of a } \\
\text { procurement } \\
\text { platform }\end{array}$ & $\begin{array}{l}\text { Creation of a } \\
\text { farm incubator }\end{array}$ & $\begin{array}{l}\text { Development of } \\
\text { organic farming } \\
\text { and short } \\
\text { circuits }\end{array}$ & $\begin{array}{l}\text { Reduction of } \\
\text { the use of } \\
\text { pesticides and } \\
\text { nitrates }\end{array}$ \\
\hline Area & \multicolumn{2}{|c|}{$\begin{array}{l}\text { Drôme valley } \\
\left(2,200 \mathrm{~km}^{2}\right)\end{array}$} & $\begin{array}{c}\text { Paris } \\
\text { Saclay Plateau } \\
\left(76 \mathrm{~km}^{2}\right)\end{array}$ & $\begin{array}{l}\text { Basin } \\
\text { Seine-et-Marne } \\
\quad\left(5,912 \mathrm{~km}^{2}\right)\end{array}$ \\
\hline Environment & \multicolumn{2}{|c|}{ Rural } & Peri-urban & Rural \\
\hline $\begin{array}{c}\text { Main } \\
\text { farming } \\
\text { systems }\end{array}$ & \multicolumn{2}{|c|}{$\begin{array}{l}\text { Orchards, grains, seeds, goat and } \\
\text { sheep rearing, vineyard, aromatic }\end{array}$} & \multicolumn{2}{|c|}{ Field crops } \\
\hline $\begin{array}{l}\text { Number of } \\
\text { farms }\end{array}$ & & 00 & 8 & 2,638 \\
\hline $\begin{array}{l}\text { \% of utilized } \\
\text { area farmed } \\
\text { organically }\end{array}$ & & $\%$ & $5 \%$ & $1.2 \%$ \\
\hline
\end{tabular}




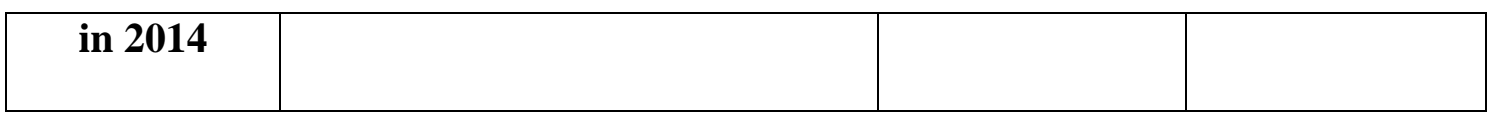

Table 1 - Characteristics of our case studies and of their locations

We studied all four cases following an ethnographic approach drawing on comprehensive interviews, archives and participant observation, in order to analyse the evolution of the visions and practices of the actors and the evolution of their networks ${ }^{6}$.

\section{Description of the four initiatives}

In this section, we present our four case studies: Agricourt's procurement platform, Compagnons de la Terre's farm incubator, AMAP Ceres's box scheme and the Aqui'Brie initiative.

\subsection{Agricourt: a community procurement platform for local and/or organic products}

The first of our case studies is a community procurement platform which initially emerged from an awareness-raising initiative launched by a group of parents in a neighbour area of the Drôme valley. In 2009, they founded a not-for-profit association named Court-circuit to raise elected officials' and other parents' awareness in order to develop local and fresh food procurement for school canteens instead of agro-industrial catering. Their goal is for pupils to

\footnotetext{
${ }^{6}$ The cases in the Drôme valley were studied in the framework of Sibylle Bui's PhD thesis (2015) and the cases in the Paris Basin were studied in the framework of Aurélie Cardona's PhD thesis (2012).
} 
"reconnect with seasonal, tasty and quality food, and to reduce food waste" "In the first year, around forty parents joined Court-circuit. They rapidly realized that trying to raise awareness of incumbent actors was not sufficient and that school canteens wishing to purchase local products faced logistical barriers. They then decided to diversify their actions and to contribute more actively to overcoming these barriers, and considered the option of creating a procurement platform.

To conduct a feasibility study, they claimed financial support from several local and regional public authorities. They gradually built up a network of potential financial partners, which resulted in the organization of a meeting to discuss Court-circuit's project and its funding.

Participants in that meeting included the community of municipalities of the Val de Drôme $\left(\mathrm{CCVD}^{8}\right)$, which was involved in the Biovallée project and therefore was aiming to increase local and/or organic procurement in local catering to $80 \%$ of total purchases, by setting up a dedicated local procurement platform. A genuine alliance emerged between Court-circuit and the CCVD that shared a common objective (fostering local procurement), which made it possible to get the other public authorities involved and encouraged Court-circuit to implement the platform in the Drôme valley.

These interactions between Court-circuit and its financial partners led its members to broaden the objective of the feasibility study. It developed into a wider market analysis to identify the barriers to the development of short food chains (not only for local catering) and investigate to what extent local producers, consumers and catering were willing to commit to developing short food chains. The underlying project had two purposes: "raising awareness to generate

\footnotetext{
${ }^{7}$ Gîtes de France de la Drôme press folder, 2010, p. 5.

${ }^{8}$ The CCVD is one of the two main communities of municipalities of the valley, which at the time of our study brought together 36 of the 103 municipalities in the valley.
} 
demand" and "structuring supply and making products deliveries to clients". . Conducting this study in 2010, Court-circuit members met with some local farmers who were interested in working more on their local market, and other inhabitants who were interested in local sourcing for their own consumption. Together, these inhabitants, farmers and members of Court-circuit decided to develop the missing tool to structure local food chains: a procurement platform.

While none of the members of the organization were farmers, their interactions with farmers through this study raised their awareness of farming issues and of the need to include farmers in the project in order to defend their interests. Court-circuit then decided to create a second organization named Agricourt, whose board is comprised of consumers and farmers, to implement the procurement platform. The platform was launched in 2011, and soon afterwards farmers and consumers involved in the organization worked on drawing up principles and rules which were formally laid down in a Charter in 2012. The content of this Charter reflects the evolution of the project. The general objective is to "durably link local faming to the inhabitants and professionals of the territory"10: while it initially focused on "school canteens and children's food practices", the project shifted to a broader range of objectives. The "ethical approach" initially supported exclusively by consumers in the Courtcircuit organization broadened its remit from the geographical origin of products and types of food chains, to modes of coordination and interactions between concerned actors. The creation of directs links and partnerships between farmers and individual or collective consumers was supported by "joint governance to ensure transparency and exchange between

\footnotetext{
${ }^{9}$ www.courtcircuitdrome.fr

${ }^{10}$ Agricourt charter, $1^{\text {st }}$ article, 2012.

${ }^{11}$ Words of Agricourt's president during the 2013 general assembly.
} 
farmers and consumers" $" 12$, which was extended to catering representatives in 2013. Moreover, the charter defined a new objective: to support the setting-up of young farmers and small-scale agriculture. This shows that farming issues were indeed integrated into the project. Agricourt's business rules and sourcing practices were then defined according to these criteria (e.g. lower trade margins on local and small-scale farming products to offer local farmers higher prices and at the same time encourage customers to buy these products). With the enrolment of various actors representing the different components of the food system and the construction of innovative business practices and coordination modes, Agricourt thus led to the emergence of a sociotechnical niche.

At first the platform only worked with a few schools that had been identified during the feasibility study, and small groups of inhabitants - supporters of Court-circuit - who constituted small purchase groups to buy their food products from Agricourt. The activity essentially relied on volunteer work, which amounted to 1,000 hours in the first year. Public financial support (investment and operating aid from CCVD and State-funded contracts) allowed for the rapid development and professionalization of the activity: by 2013, Agricourt had enhanced skills and workforce and employed four people. It now works with 36 local producers and around 40 local purchase groups, nurseries and primary and secondary schools. In other words, it reaches a very large number of families and children and thereby significantly impacts local distribution and consumption patterns. For instance, in 2015, 60\% of all the meals served in the Drôme valley's school canteens were prepared with products supplied by Agricourt, and consequently mainly by local, small farmers who had been adequately remunerated.

\footnotetext{
${ }^{12}$ Agricourt charter, $2^{\text {nd }}$ article, 2012.
} 


\subsection{Compagnons de la Terre's farm incubator}

Support for the setting-up of new farmers is a critical issue in the Drôme valley, as elsewhere. In 2006, three employees of a local public vocational training agricultural centre, joined by a farmer and two back-to-work organizations with the support of the Diois community of municipalities $\left(\mathrm{CCD}^{13}\right)$, created an organization named Compagnons de la Terre ("Companions of the Earth") to address this issue. Noting that few students succeeded in setting up after training in that centre - especially students without a farming family background and/or with an atypical project -, their hypothesis was that these students' difficulties were due to the unrealistic nature of their projects, but also to their lack of professional network which made it difficult for them to be informed about land availability and to gain owners' trust. They thus identified a "missing link" within the conventional farm set-up system, handled by mainstream agricultural actors (mainly by the Chamber of Agriculture). The aim of their organization was to create a farm incubator complementary to this existing set-up system, where people could test their project's feasibility for one or two years and build up a social network.

Thanks to the CCD, they accessed 1.5 ha of land in 2006 and were able to buy some equipment. The farm incubator was implemented in 2008 in Die, the main country town in the eastern part of the valley. Three young future farmers settled there in 2008 and 2009 and thus gained access to land and equipment to test their project before possibly investing. Due to its small size, the farm incubator cannot welcome more young farmers.

\footnotetext{
${ }^{13}$ The CCD is the other main community of municipalities of the Drôme valley, encompassing 52 of the 103 municipalities in the valley.
} 
Right from the beginning, Compagnons de la Terre's idea was to expand to other sites, but in 2009 a change of direction at the training centre and a change in the political majority in the CCD dried out the support they used to have from these institutions and their expansion objective was put on hold. As the farm incubator is exclusively managed by volunteers, the lack of human resources hinders the search for other financial resources.

In 2010, the community of municipalities of Val de Drôme (CCVD) that was considering implementing a farm incubator in the framework of the Biovallée programme took advantage of an opportunity to rent an 8.5 ha farm, appointed Compagnons de la Terre to manage it, and gave them the financial resources to recruit a coordinator. This CCVD's support allowed Compagnons de la Terre to move forward with their project, while symmetrically, Compagnons de la Terre's action, which was very innovative in the French context, allowed the CCVD to implement a farm incubator as planned and contributed to building the image of the "Biovallée" as an innovative territory, of which this incubator has become a flagship initiative.

In 2012, this farm incubator hosted seven project developers. Most of them had projects based on direct sale and wished to develop processing and on-farm marketing activities. In order to support them on all aspects of their projects, Compagnons de la Terre tailored the farm incubator, once again with public subsidies from the CCVD, and set up an on-farm marketing point, as well as refrigerated storage and processing facilities. In other words, since then, the farm incubator provides future farmers not only with land and farming equipment, but also with storage, processing and marketing facilities.

Concern about the future of project developers, who still found it difficult to set up despite their experience in the farm incubator and despite its positive impact on the image of organic 
farming $^{14}$, also led Compagnons de la Terre to further diversify their actions and to tackle the land access issue more directly. In 2012, they decided to create decentralized incubators. These were to provide a legal framework for landowners who agreed to make some land available for young farmers, to transmit their know-how, to help them technically and possibly lend them some equipment, often with their retirement in mind. But this appears to have been more difficult than expected and few farmers answered their call. That is why, together with CCVD, they created another complementary tool. When a farm becomes available locally, CCVD finances its acquisition from a Land Intervention Fund that it created in 2012, and entrusts Compagnons de la Terre with its management. The idea here was to give a project developer access to land, if needed, as well as the opportunity to test his/her activity for two years, in addition to the possibility of buying the land from CCVD. CCVD would then be able to buy another farm for another set-up project. The implementation of this new farmland management system required endorsement by, and continuous coordination with, the national farmland management organization SAFER ${ }^{15}$. Compagnons de la Terre and CCVD thus created a highly innovative tool, implementing new rules on farmland access. Whereas in France the farmland allocation scheme is mainly in the hands of mainstream agricultural actors and often benefits existing farms, in the Drôme valley a new system is emerging, based on other selection criteria of candidate-farmers, and led by local authorities and civil society. In summary, initially, the aim of Compagnons de la Terre's initiative was

\footnotetext{
${ }^{14}$ As the officer in charge of Agriculture for CCVD told a group of scholars visiting the farm incubator: "In this area, it's mostly intensive agriculture: cereals, seeds... And the farmers around wouldn't lend their land to young organic farmers, because they thought they couldn't do proper work. Thanks to the incubator, they can see that they are not long-haired, lazy ex-urban people but on the contrary, that they work hard and well" (December 2011).

${ }^{15}$ SAFER is the national organization in charge of farmland management. When farmland becomes available, SAFER buys it. The land is then allocated to a candidate-farmer, depending on the advice of a committee in which the Chamber of Agriculture plays a major role (in defining the criteria on the basis of which to choose between the candidates).
} 
merely to implement farm incubators to encourage agricultural set-up. However, after a few years and thanks to the cooperation of local authorities, it started having an impact not only on agricultural set-up but also on the image of organic farming and especially on land access and on local public policies (Bui, 2015).

\subsection{The AMAP Ceres box scheme}

The third case study is an initiative launched by a group of city-dwellers from a peri-urban area of Paris (Saclay Plateau) and aims at encouraging local farmers to produce food for local consumers to legitimize the preservation of a farmland area threatened by urbanization. The initiative came from a group of city-dwellers who lived on the foothills of the Saclay Plateau. They often met at local events or at the local organic restaurant; some of them supported Pierre Rabhi ${ }^{16}$ as a candidate in the 2002 presidential election. They appreciated the wooded surroundings of the plateau and found the plateau itself enjoyable for walking and cycling, but they all made the same observation: urbanization was growing and gradually encroaching on farmland. In order to create interdependence between farmers and non-farmers to foster the preservation of the farmland, this group, influenced by the ideas of Pierre Rabhi, made contact with the farmers (who were all conventional and mainly grain farmers) to build up a local food chain. Only one of the eight farmers of the plateau answered their call and even though he was not totally convinced by their ideas at the time, together they decided to create an AMAP (CSA-type box-scheme) in 2003. This project was a big challenge for this

\footnotetext{
${ }^{16}$ Pierre Rabhi is a French writer, farmer and environmentalist. He advocates for a society that is respectful of populations and land and supports the development of agricultural techniques that take care of the environment, preserving natural resources.
} 
conventional cereal farmer: it involved farming new crops and developing environmentally friendly practices.

"I was not at all interested in sustainable development, organic farming, environmental concerns, etc. The consumers of the AMAP were already very involved in these issues. I had to catch up with them. On their side, they had to understand that a business does not move like that, overnight" (Farmer from the Saclay Plateau).

However, the AMAP gradually grew and in 2015 it supplied 350 households.

In parallel with this first initiative, the group of city dwellers also developed other actions. In 2005, the farm involved in the AMAP was threatened by a road construction project. The members of the AMAP created a Property Investment Company named "Terres Fertiles" in order to raise funds to buy the land affected by this project. Most of the members of the AMAP provided funds, as did people from all over France concerned by the issue of farmland urbanization or willing to support the initiative. They eventually bought the land, thereby ensuring the viability of the whole farm.

A few years later, in 2010, a new urban planning project to develop a big university campus emerged and threatened the farmland of the Saclay Plateau. In order to reinforce their action, the initiators of the AMAP developed a project to build a short supply chain for local catering. Through this initiative they wanted to involve other farmers in the area in a process of transition towards sustainable farming, but also local authorities and other potential consumers. They first participated in a competition for ideas for the Saclay area organized by the government, to foster local stakeholders' involvement in future urban planning. During this competition they proposed a first formalization of their vision of the future of the plateau based on an environmentally friendly agri-food network supplying household consumers but also local catering and especially the businesses, universities and schools already located on the plateau. While their proposal was not selected, they pursued the development of their 
action at local level. In 2011, they re-launched an organization named "Terre et Cité", comprised of local government officials, environmental groups representing civil society and, above all, almost all of the farmers on the plateau. Thanks to the public funds provided by the community of municipalities of the Saclay Plateau and some other municipalities, a project manager was hired to convene workshops with farmers and local catering, and to formalize the commitment of various stakeholders - especially local municipalities in charge of school canteens - to the project and its implementation. This led them to develop a local food system where canteens can get - among other things - eggs, bread and yoghurt produced by farmers from the plateau. Four farms (that is to say, $50 \%$ of the farms on the plateau), of which three are now organic, have diversified their production since this initiative and now supply local chains.

\subsection{The Aqui'Brie initiative}

The last initiative is located in the Seine-et-Marne département and was launched in 1994, by a committee of water users from the Champigny groundwater table, comprised of local industry representatives, the Chamber of Agriculture, the water managers, the municipalities and the département and regional authorities. The committee's first objective was to monitor the quality of the groundwater table and the distribution of the water between all its users. However, with the growing quality issue raised by the presence of nitrates, pesticides and herbicides, the committee had to move into action. In 2001, it became an organization for the protection of water and expanded its membership by inviting representatives of farmers' unions. With this new statute, the organization could act as a project manager and develop actions to reduce polluting practices. The organization was also able to hire two engineers (an agronomist and a hydrogeologist) and a facilitator. 
Initially, the organization focused on non-farming actors' practices (green areas besides roads and railways, golf courses, etc.). In 2004, the organization developed its first action targeting the agricultural world with a study on local farming practices and by participating in the definition of the technical specification of a new agri-environmental scheme to reduce the use of pesticides and herbicides and protect biodiversity. The necessity of the organization's involvement in agricultural issues has been reinforced by a government report revealing that 199 municipalities of the Seine-et-Marne département supplied households with drinking water that did not comply with national and EU regulations. Not too long after this report was released, the organization took charge of the agri-environmental scheme in a catchment basin in the South of the Seine-et-Marne département covering 12 municipalities, and hired a computer engineer to take care of the agricultural practice database, a public relations manager and a second facilitator specialized in agricultural practices.

With the development of this organization's activities surrounding agricultural issues, the local Chamber of Agriculture began to get more involved in the issue of water pollution. Moreover, in 2006, the government published a "plan for water for the département", which among other things proposed subsidies for equipment to prevent accidental pollution on farms and offered the possibility of joining a new territorial agri-environmental scheme to protect water resources by reducing the use of pesticides and herbicides. Five catchment basins in Seine-et-Marne were concerned by this new agri-environmental scheme and the Chamber of Agriculture, the organization for the protection of water and the local water management company were in charge of the scheme in the different catchment basins. Ultimately, $25 \%$ of the farmers in priority areas joined the agri-environmental scheme. More importantly, the implementation of this agri-environmental scheme encouraged collaboration between these actors, who pooled their data about farming practices and developed shared events and training to help the farmers who were part of the agri-environmental scheme to change their 
practices. The involvement of several catchment basins of the département also led to the general mobilization of the actors of the département (agricultural firms, municipalities, etc.) around the problem of water quality.

\section{A generic pattern in niche trajectories}

We modelled the trajectory of each initiative, according to three criteria and their evolution over time: the actors involved in the initiative, the main objectives, and the impact on agrifood practices. The modelling of the initiatives' trajectories allowed us to compare their capacity for regime reconfiguration and the mechanisms of this reconfiguration.

The four initiatives we described above all had very different initial objectives. Their initiators were also very different: the creation of Agricourt and AMAP Ceres originally emerged from civil society on the margins of the regime, whereas the Compagnons de la Terre's farm incubator and Aqui'Brie originally emerged within the regime and were endorsed by agricultural and/or institutional actors. Despite these differences, we were able to identify mechanisms common to all four trajectories, and differentiate between three stages: first the emergence of the initiative; second the construction of a sociotechnical niche through the enrolment of new actors, leading to a diversification of its activities; and third, the construction of an alternative model allowing for further enrolments and leading to the redefinition of the network of actors concerned by the issue.

In the first stage, the initiative has a specific focus and includes a limited range of actors, mainly individuals from a single social group or stakeholders traditionally in charge of the issue: Court-circuit sought to change children's food and their food-related behaviour through 
the development of local catering; the inhabitants around the Saclay Plateau wished to preserve their living environment and therefore sought to reconnect inhabitants and farmers; employees of the farming training centre wished to complement the existing farm set-up system with a farm incubator, to adapt the system more fully to all young farmers' profiles; and water users in Seine-et-Marne wanted to improve the management of drinking water quantity and quality.

During the second stage, these individuals or organizations gradually realize, as they implement their action, that the issue they want to tackle is related to the way various actors are coordinated, and that in order to have a greater impact, their action needs to be complemented with further changes in the agri-food system. This leads them to widen the circle of actors involved and to try to enrol new actors. As a result, they create a multi-actor organization for various actors to voice and discuss their viewpoints: Agricourt, Compagnons de la Terre, AMAP Ceres, and Aqui'Brie. As the actors involved in each initiative developed a better understanding of the interdependent barriers they were trying to break down, they defined broader goals and a shared vision of the future, and created new forms of interaction between actors and new practices or infrastructures. For example, as the candidates for the farm incubator wished to develop direct sale, Compagnons de la Terre created complementary storage, processing and marketing facilities within the farm incubator. Later on, they built up a network of tutors and developed the decentralized incubator concept to foster technical and social learning. Agricourt did not merely seek to develop local catering, it also wished to support small-scale agriculture and tailored its business strategy accordingly. For example, on its market price list, it only proposes local products, even if it can - and potentially does, if requested by a customer -, provide other types of products that it buys from more industrial wholesalers. From a multi-level perspective, this second stage is when the initiative becomes a niche per se, i.e. a small network of actors, developing radical innovations and new 
sociotechnical practices. During this second stage, new enrolments allow the niche to gain stability (more local customers and suppliers for Agricourt, more candidates for Compagnons de la Terre and enrolment of CCVD for both of them). The objective of the members of the AMAP on the Saclay Plateau was first to connect farmers and city-dwellers to create a small local food chain to legitimize the preservation of farmland. After a few years, and because part of the land of the farmer involved in the AMAP was threatened by a road construction project, the members of the AMAP (the consumers and the farmer) realized that this was not sufficient. At that moment, and because they were able to enrol other actors specialized in planning (the organization Terre de Liens ${ }^{17}$ ), they created another organization to buy the farmland and protect it from urbanization - quite an innovative practice at the time. Lastly, when the committee working on water issues became a multi-actor organization and changed its legal statute to be a civil society organization, it was able to define actions first to change practices in public green spaces, and then to work with farmers as their representatives were members of the organization.

During the third stage, mechanisms of coevolution between practices, visions and interactions between the actors involved in the niche lead to the construction of an alternative model: a food supply chain model for Agricourt and AMAP Ceres, a farm set-up and farmland management model for Compagnons de la Terre, and a water issue management model for Aqui'Brie. For example, the farm incubator initially only aimed to develop the "missing link" within the existing system, but it ended up fostering the creation of a whole alternative land access system. Agricourt sought to develop local catering, and ultimately turned to the creation of a "business unlike others" and an "alternative economic model". This process led

\footnotetext{
${ }^{17}$ Terre de Liens is a civil society organization created in 2003 to address the difficulties faced by organic and peasant farmers in securing farmland. Terre de liens first supported collective ownership schemes, wherein farmers received contributions from their kin, consumers or the local community to set up an investment business to buy their land.
} 
niche actors to further define their objectives and induced profound change in the network of actors involved: Agricourt's governance of the food chain was expanded to include restaurateurs, canteen managers and processors; Compagnons de la Terre broke away from the regime's incumbent network by asking local authorities rather than the Chamber of Agriculture for support to set up decentralized incubators; a large group of actors was enrolled by Aqui'Brie around the issue of water management and by AMAP Ceres around the creation of a local food network. This has also led to a diversification of their activities: for Agricourt, supplying company canteens and supporting young farmers; for Compagnons de la Terre, setting up an alternative training and extension model and managing farmland; for AMAP Ceres, creating a local project and local short food chains to supply canteens; for Aqui'Brie, involving other farmers "and developing extension activities. Ultimately, these initiatives, which all had a specific starting point corresponding to a single component of the sociotechnical system, impacted on various components of the agri-food system. Agricourt impacted on children's food-related behaviour and inhabitants' consumption practices, and created local economic and short-chain opportunities for farmers. Compagnons de la Terre impacted on agricultural set-up by helping young future farmers to test their projects and build up a social network. This organization also fostered new modes of transmission of knowledge and know-how with the network of tutors and the decentralized incubators, and strongly influenced local public policies. Its influence on local public policies is attested by the facts that the farm incubator is one of their flagship actions, and that the local authorities, who no longer rely exclusively on the Chamber of Agriculture with regard to land access (thanks to the Land Intervention Fund), are now supporting Compagnons de la Terre's criteria for farmland allocation. The initiative of the Saclay Plateau impacted on inhabitants' consumption practices, the farming and commercialization practices of local farms, local public authorities' urban planning and consequently local governance. The Seine-et-Marne 
initiative impacted on the use of pesticides and herbicides as it launched several agrienvironmental schemes and organized advisory services to offer new forms of training.

The significant impact on practices, strategies and alliances of some regime actors at the local scale proves that effective niche-regime linking, leading to a regime reconfiguration, is occurring within the local agri-food systems that we studied. Figure 1 graphically displays the generic pattern of the trajectories of the niches studied, and sums up theirs impacts on the regime at the local scale:

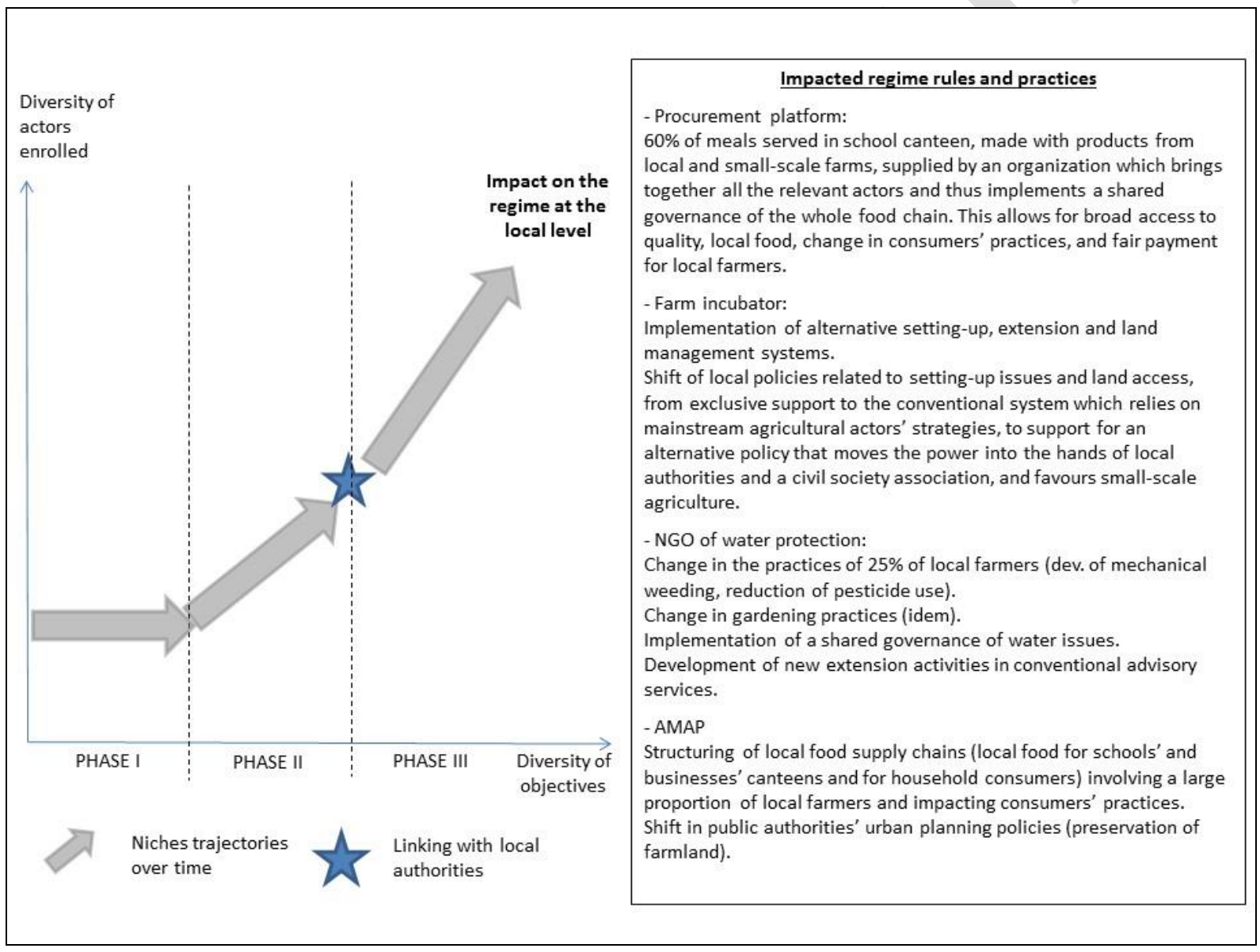

Figure 1 - Three development stages in niche trajectories: the emergence of the initiative (Stage I); the construction of a sociotechnical niche through the enrolment of new actors into the initiative, leading to the diversification of objectives and activities (Stage II); the construction of an alternative model impacting various components of the agri-food regime 
(Stage III). The increasing diversity of actors involved in the niche progressively leads to the construction of an alternative model, and the enrolment of local authorities, through spillover effects, then triggers deep changes in practices, strategies and alliances of some regime actors at the local scale.

Our analysis of four case studies brings new insights on the mechanisms of niche-regime interaction that we will discuss in the next section.

\section{Discussion: niche development, linking with the} regime and regime reconfiguration

In this section we show that our approach allows us to identify mechanisms common to the four case studies, through which these initiatives develop and link with regime actors, and through which regime reconfiguration occurs at the local scale. We show that niches' activities and the enrolment of actors lead to a gradual reconfiguration of the regime, first through the construction of shared visions of agriculture and/or food issues and the construction of the related network of relevant actors, and second by embedding these visions in local policies and public action.

\subsection{Changes in visions of agriculture and of the network of relevant actors}

In all our case studies, the initiatives were not built to support the development of new technology, as organic farming and low-input practices have been empirically tested for many years by farmers and by research and extension services. The core innovation supported by each niche is not merely technological but also social and organizational. The niche actors 
combined social and technical innovations around the procurement platform, the farm incubator, the box scheme and the actions surrounding water issues, but not around a new, emerging technology (a single technology or a combination of new technologies). Inside their multi-actor organizations, the novelties promoted are new forms of coordination and associated new practices: new commercial and canteen procurement practices for Agricourt and AMAP Ceres, new land provision and knowledge transfer practices for Compagnons de la Terre and new training and education programmes for Aqui'Brie. These modes of coordination and practices coevolve over time, leading to the collective construction of a vision of both the type of farming systems that should be supported and the role of the different actors in the agri-food system.

At first the members of Court-circuit wished to encourage the use of fresh quality food and seasonal products in children's meals, instead of agro-industrial processed food. Through their interactions with local, small-scale farmers, they learnt about the social role that agriculture can play and integrated the preservation of smallholdings to the objectives of the platform. Through their interactions with the local authorities who wished to develop organic farming, they were sensitized to the issue of the impact of farming practices on the environment and decided that products that are not locally sourced should be organic. Of course, they also had an interest in contributing to this objective in order to gain public financial support. After a few years, some of the farmers who belonged to Agricourt converted to organic farming, not only for the better prices they could get from their products but also because they wanted to have a less negative impact on the environment and support the territorial project of building a "Biovallée".

Compagnons de la Terre sought to encourage small-scale and organic farming from the creation of the organization in 2006, as written in its bylaws. The project developers hosted by the farm incubator strongly influenced its activities. Not only did they then wish to implement 
smallholdings, they also wished to develop on-farm processing and direct sale, which is why the farm incubator built storage, processing and marketing facilities. As Compagnons de la Terre, together with local authorities, recognized that the farm incubator was not sufficient to help young farmers set themselves up and that access to land was a key issue, they decided to create an alternative land management system. Initially, the Compagnons de la Terre's farm incubator was conceived as a complementary tool to the set-up system in place, as it was defined as the "missing link". Compagnons de la Terre volunteers supported project developers in their life project, but these had to fit within the existing system, governed by the agricultural mainstream extension service (Chamber of Agriculture) which was expected to provide them with technical support and as such was involved in the farm incubator's steering committee, along with the vocational training centre and the community of municipalities. However, this steering committee gradually stopped working. We assume this is due to the particular positioning of the project. Compagnons de la Terre's mission is not merely to create a farm incubator, it is explicitly "to support organic farming" and "to develop new forms of transmission of knowledge and know-how" ${ }^{\prime 18}$, i.e. it is exclusively focused on organic farming and supporting new forms of training and extension. These were probably not part of the Chamber of Agriculture's priorities and too far from its vision of agricultural development, which explains its withdrawal. The strong alliance between Compagnons de la Terre and local authorities now forms the basis of a new network supporting agricultural set-up and capable of managing farmland allocation.

On the Saclay Plateau, the non-farming inhabitants and the farmers initially shared neither the same vision of the plateau, nor the same values at all. For the non-farming inhabitants, the plateau was an open space for leisure; whereas for the farmers, the plateau was a "working

\footnotetext{
${ }^{18}$ Bylaws of the Compagnons de la Terre, $2^{\text {nd }}$ article, 2006.
} 
tool" that they could abandon - in the early 2000s, some farmers were thinking of leaving the area to settle somewhere else. Nor did they necessarily share the same values.

"It is complicated to create a relationship between people who don't have the same vision at all about what sustainable development is [...], or the protection of earth [...] Six years ago [when the AMAP was created], I wasn't open to this reflection yet" (Farmer from the Saclay plateau).

The situation was similar in Seine-et-Marne, where the organization involved in water protection saw the territory as a catchment basin threatened by nitrate and pesticide pollution, where farmers also saw it as a "working tool", where copses are a nuisance because they host animals that destroy crops, or as a "non-landscape" - which does not encourage the adoption of environment-friendly practices. In both the Saclay Plateau and Seine-et-Marne cases, the repeated meetings and discussions between the actors involved around each of the initiatives gradually led to a shared vision of the local issues and of the territory.

While initially some of the members of the AMAP only wanted organic products, they eventually realized that it was a big change for the farmer, and that they had to help him to learn about environmentally-friendly practices. As a result, they put him in touch with other organic farmers involved in AMAP, but also with potato specialists, as potato was a new crop for this farmer. The same approaches were developed to buy the land threatened by the road construction and for the creation of a short food supply chain for local canteens.

In Seine-et-Marne, while the organization's employees are still often called "environmental activists" ("écolos"), some farmers recognize that the organization has made them aware of environmentally friendly practices and that this was facilitated by the fact that the organization not only expanded its panels for training about environmental farming practices but also made contact with practitioners to show the farmers that it is possible to farm differently: 
"The organization took us to meet organic farmers who work with tine harrow [...] or an automatic hoe, and we decided to invest to buy one..." (Farmer from Seine-et-Marne).

This gradual change in farmers'-visions was also facilitated by the involvement of all of the département's agricultural actors in water issues and especially in the implementation of the agri-environmental schemes, as we will see in the next section of this discussion.

Thus, all these initiatives not only invented new practices and new forms of coordination between actors, they gradually built an alternative vision of agriculture and of the network of "relevant" actors, i.e. those who should be involved in governing the issue. This alternative vision fostered further enrolments (catering representatives in Agricourt, the network of tutors of the farm incubator, etc.), further exchange and further diversification of activities. The combination of alternative practices, forms of coordination and visions then shaped new models for each component of the local agri-food system. The practices and rules developed inside each initiative ended up more broadly impacting practices and rules outside the initiative.

\subsection{The embedding of new shared visions in the regime through public policies}

The regime is the set of formal and informal rules and routines embodied by the sociotechnical system (Geels, 2002; Rip and Kemp, 1998), which initially revolve around conventional farming. We can therefore consider that the regime rules and routines are initially embodied in local policies and public action. In other words, when niche actors manage to influence local policies through their interactions with local authorities, they have an impact on part of the regime.

This influence on public action and consequently on the regime is reflected in the alignment of niche actors' and local authorities' visions and activities. In the Drôme valley, when the 
Biovallée programme was launched in 2009, local authorities planned actions to support downstream businesses and industries, in order to generate local demand for organic products and thereby encourage conversions to organic farming. They initially supported the implementation of an industrial platform. One of the leading French companies in the processing and wholesale of organic products opened up an organic procurement platform for school canteens in the Drôme valley in 2010, thanks to strong financial support from the Biovallée programme, but closed it in 2012 on the grounds that it was not profitable enough. In 2009, local extension services (Chamber of Agriculture) had also carried out a study on local procurement for school canteens in a close area in order to respond to an injunction from local government. At the time, this issue had become a hot topic as it had been defined as a strong objective by the French government. The Chamber of Agriculture's study concluded that it had the legitimacy to organize neither local production nor supply chains for such projects, and that it had no interest in doing so. Therefore, when Court-circuit met with the Drôme valley's public authorities about their platform project, they brought along answers in line with the local political project, which regime actors (such as the Chamber of Agriculture) could not (or would not) provide.

In the Biovallée programme, there was no question about the type of organic farming systems and the type of coordination to support within the agri-food system. The interactions between public authorities and niche actors upholding an alternative vision of organic farming (smallscale, autonomous organic farming, integrated in the social rural fabric) and a critical understanding of the agri-food system gradually triggered a shift in local public policies. Local authorities then began to support small-scale agriculture and actions challenging the functioning of the sociotechnical system and leading to a redefinition of the network of relevant actors for these issues. 
Elected officials became aware that niche actors, because they were inventing new forms of market organization and new interactions between food chain actors, and because they saw their activity as a public utility service, were the only ones willing to supply micro- and remote organizations (such as micro-nurseries taking care of less than a dozen children) with fresh, local and/or organic food. Moreover, as they were implementing fair business practices, the added value was being distributed better between the food chain actors. Niche actors thus appeared as the ones best able to implement the type of activity that best contributes to rural development.

The adjustments made to the public procurement branch of Biovallee reflect the influence of Agricourt on the local political project. Local authorities stopped believing that Biovallée's public procurement strategy should be based on agro-industrial organic firms establishing themselves in the valley. Moreover, they led their own operations to complement Agricourt's activity and Court-circuit's awareness campaigns. Agricourt charges much higher prices than more industrial platforms, due to its size and its ethical approach (since small-scale conventional and organic products are more expensive than more industrial ones and because its trade practices are fairer). Local authorities decided to launch a complementary programme to train canteen cooks to use fresh products and to tailor menus (reducing the share of meat) so as to maintain low prices for parents. This shows that Agricourt's dynamic has had a concrete impact on the rules and routines of the regime and how local authorities' visions and actions, i.e. local policies, gradually aligned with those of more alternative actors.

The case of the farm incubator also illustrates how niche actors have influenced local policies and public actions and how their visions of agricultural set-up issues and of the network of relevant actors were integrated into the regime through an alignment process. Initially, the Biovallée programme planned to build several eco-industrial parks, in order to create the conditions for firms working in industries exploiting bio-resources (including the organic food 
industry) to settle in the Drôme valley. Aside from this general objective, it intended to possibly integrate farms incubators in these eco-parks, for farming projects requiring small surface-areas. The implementation of farm incubators was thus a secondary objective, on the fringes of the much broader industrial and economic development goal of promoting innovative farming projects and unrelated to the development of organic farming and to set-up issues.

This goal was sidelined until 2011, when the community of municipalities of Val de Drôme had the opportunity to buy a farm located in a cereal plain, a sector in which organic farming still suffers from a poor image. Under the impetus of Compagnons de la Terre, the farm incubator project shifted from mere set-up support to encourage economic activity, to a tool with strong symbolic significance aimed at fostering the creation of small-scale organic farms and changing the image of organic farming.

“This action helps to show elected officials' support to young people setting themselves up [in agriculture]. Its value is mostly symbolic; it serves to show our support to organic farming in a place like here [intensive cereal and seed production area], where the farming incubator is like an organic island [...], to shift this industry's mindset." (Officer in charge of Agriculture for the CCVD, presenting the farm incubator to a group of scholars, 2013).

The alliance between Compagnons de la Terre and local authorities strongly influenced Biovallée's political orientation by changing the local authorities' vision of the type of agriculture that should be supported (not only organic, but also autonomous, small-scale farming). This subsequently influenced the strategies of other regime actors. For example, after 2013 the Chamber of Agriculture, which received 10\% of its annual budget in subsidies from the local authorities, started launching new actions in line with this new vision of agriculture, such as a support programme around farm-saved seeds and an experimental programme on highly diversified farming systems. As we have shown, it also had a strong 
impact on public action by triggering the creation of a new, more direct form of farmland management by local authorities.

This alignment process is also observable in the case of Aqui-brie. For a long time some agricultural actors, especially the Chamber of Agriculture, which represents the interests of the majority of local farmers, saw Aqui-brie as a "utopian" environmentalist organization. However the multiplication of campaigns surrounding agricultural practices and water protection gradually convinced the local government and then the Chamber of Agriculture that water issues should be tackled from an agricultural perspective. Little by little, it appeared that the actions proposed by the organization could have a positive impact on water issues and at the same time rehabilitate the image of cereal farming.

Collaboration with local authorities can also reinforce niches and increase their recognition. By cooperating with local authorities and contributing to the Biovallée programme, both the farm incubator and the Agricourt platform benefited from the public communication strategy around the Biovallee programme, which shined the spotlight on these pilot initiatives. Agricourt received an innovation and social economy prize from a private foundation in 2014 . The farm incubator gained national recognition when it won a regional innovation prize from a major private foundation in 2013 and was asked to give testimonials and share its experiences by dozens of organizations all over France. This recognition comforted the local authorities in their support to these initiatives. It also benefited the project developers: "We have more leeway than in an ordinary set-up, to build up a network, to make ourselves known. We gain credibility with neighbour farmers. If we look for land in this area, we are not unknown... We also benefit from the regional weight of the organization, which is one of the flagships of the Biovallée programme" (A future farmer hosted by the farm incubator, quoted in Compagnons de la Terre's Newsletter no. 2, December 2011). This recognition also comforted niche actors in pursuing their project, leading them to broaden their objectives and 
ultimately resulting in the construction of an alternative model (shift from Stage 2 to Stage 3 of the initiatives' trajectories).

In the other case studies, collaboration with the local authorities especially reinforced the farmers' recognition of the niches. In the case of the Saclay Plateau, the local authorities' involvement in the local food supply chain project and their formal commitment to buying local products for their canteens convinced several farmers to join the project. In the case of the Seine-et-Marne département, the organization's collaboration with government services to develop agri-environmental schemes and of course the subsidies that derived from this collaboration were a crucial argument to enrol farmers.

In all our case studies, local authorities monitored the initiative thoroughly, although not simultaneously, in all the initiatives. Thanks to the familiarity they thus developed, and to their participation in local governance arenas, niche actors were able to embed their project in local public policy; in other words, they embedded, at local level, the niche - its rules, its values, its vision of agriculture and of the network of relevant actors - in the regime. New actors and new configurations of actors have taken charge of agri-food issues, according to the visions built inside the niches: farmers with atypical profiles and Compagnons de la Terre for farmers' set-up processes; consumers, small processors and small-scale farmers for the structuring of new food chains and a new supply network; water users for the definition of agricultural practices whose dissemination should be supported; and local authorities for farmland management and for the definition of agricultural policy. In other words, issues that were previously handled exclusively by agricultural or economic actors within the regime are now taken up by other types of actors, and local policy strategy and action have been profoundly transformed - both of which had been demanded by those niche actors. As discussed earlier, the strategy and action of other regime actors have consequently also been 
transformed. Hence, in our opinion, although the ongoing process is certainly the outcome of multiple, complex interactions, the four niches we studied have clearly contributed to triggering a regime reconfiguration at local level.

\section{Conclusion}

Elzen et al. (2012) propose the anchoring concept to analyse the early stages of niche-regime linking. According to these authors, successful anchoring - which they define as an interaction leading to a durable link between niche and regime -, occurs when the three forms of anchoring (technological, network and institutional) can be observed. Technological anchoring refers to the specification of the technical attributes of the novelty. Network anchoring corresponds to the expansion of the network of actors supporting the novelty, and to the intensification of contacts, exchanges and interdependencies among these actors. Institutional anchoring relates to the translation of the rules that were built inside the niche into the formal and informal regime rules. In all our case studies, these three forms of anchoring can be observed, indicating that a durable link has been built between the niches and some regime actors, and suggesting that the regime reconfiguration that these initiatives have triggered at the local scale will last.

Our comparison of four initiatives has allowed us to identify mechanisms common to the four case studies which have triggered regime reconfiguration at the local level. While Elzen et al. (2012) underlined that a challenge for further research would be to distinguish a set of characteristic patterns of niche-regime linking processes, we have identified a unique sequence pattern and have analysed the mechanisms through which some regime reconfiguration occurs. This has taken us a step forwards in the understanding of nicheregime interactions. 
We have shown that the new practices, rules and forms of interaction between actors developed in the framework of these initiatives have led to the construction of alternative visions of agricultural development issues and of the related network of relevant actors, which have gradually come to be shared by a wider range of actors, even outside the initiative. We have shown how the interactions between niche actors and local authorities have allowed for these visions and practices to be embedded into the regime at the local level and thus highlighted the crucial role of local authorities in regime reconfiguration processes. The role of public policy in such processes is also crucial as it guarantees a certain social equity in the processes of niche reinforcement for the population of farmers and consumers involved. Two of the niches studied here evolved from a quite limited if not elitist group of consumers and/or parents to a larger range of actors, including consumers initially less likely to access local and organic products.

Our analysis has also confirmed that niches may contribute to regime reconfiguration despite their small size as they can "have a tremendous impact on hearts and minds, as they suggest different ways of looking at things, different innovation pathways and different rules and norms" (Brunori et al., 2011). We have shown that the key element of these rules and norms is building new visions of farming and food issues and (re)defining the network of relevant actors. These mechanisms also transform public policy, leading to a gradual and genuine inclusion of these visions and actors into the regime.

Our results show that the initiatives studied triggered a reconfiguration of practices, rules and visions that has impacted on far more than those of the actors they formally involve. These initiatives have impacted on some of the local regime actors and do have a transformative potential. However, working on an ongoing process did not allow us to assess whether this impact was leading to a profound reconfiguration, that is to say, to a transition of the whole local agri-food system, as transitions can only be identified retrospectively. 
Our results indicate that developing new visions of farming and food is a key aspect of niche development and linking with the regime. As our analysis shows, the new visions of farming and food developed in the initiatives that we studied are radically different from the ones initially underlying the regime. This finding may seem to contradict previous studies that suggest that a certain degree of compatibility between niches' and regimes' practices and visions is necessary for a linking process to take place (e.g. Smith, 2006; Diaz et al., 2013; Ingram et al., 2015). This is most probably due to a difference of focus. We agree with Darnhofer et al. (2014) that, in order to study niche-regime interactions, it is of crucial importance to distinguish between radical and incremental changes since the latter - which are related to the internal evolution of the regime and to its adaptation to a shifting landscape - do not fundamentally transform the rules. Therefore, whereas former studies on nicheregime interactions chose to compare a broad range of initiatives, relating to both radical and incremental changes, we chose to compare only initiatives proposing radical innovations.

Combining pragmatic sociology and the MLP, our approach therefore produces original insights on the mechanisms of niche-regime interactions and regime reconfiguration. This combination makes it possible to take advantage of the analytical perspective of transition studies while at the same time addressing some of their weaknesses by focusing specifically on changes in practices, actors' networks and visions. The four case studies yielded common results regarding niche development and niche-regime interaction mechanisms, despite the fact that they are related to different agri-food issues and are located in regions with sharp contrasts in terms of demographic, institutional, cultural and farming dynamics. Considering such a wide range of case studies thus makes our analysis more robust. Other research that we have conducted suggests that this pattern of niche development and linking with the regime presents a potentially high level of generalisability (cf. Lamine et al., 2012; Bui, 2015). However, as our analysis is built exclusively on case studies related to the agri-food regime, 
further research would be needed to determine whether the findings also apply to other sectors.

\section{Acknowledgements}

The cases in the Drôme valley were studied in the framework of Sibylle Bui's PhD thesis (2015) funded by INRA and the Rhône-Alpes region, and also benefited from financial support in the frame of the ANR Dynrurabio and Core-Organic HealthyGrowth projects. The cases in the Paris Basin were studied in the framework of Aurélie Cardona's PhD thesis (2012) funded by the Ile-de-France region, and also benefited from financial support from the ANR POPSY project and INRA. We also wish to thank two anonymous reviewers who gave a variety of very useful comments on an earlier version of this paper.

\section{Bibliography}

Berkhout, F., Wieczorek, A.J., Raven, R., 2011. Avoiding Environmental Convergence: A Possible Role for Sustainability Experiments in Latecomer Countries? Int. J. Inst. Econ. 3.

Brunori, G., Rossi, A., Guidi, F., 2012. On the New Social Relations around and beyond

Food. Analysing Consumers' Role and Action in Gruppi di Acquisto Solidale (Solidarity Purchasing Groups). Sociol. Rural. 52, 1-30. doi:10.1111/j.1467-9523.2011.00552.x

Brunori, G., Rossi, A., Malandrin, V., 2011. Co-producing transition: Innovation processes in farms adhering to solidarity-based purchase groups (GAS) in Tuscany, Italy. Int. J. Sociol. Agric. Food 18, 28-53. 
Bui, S., 2015. Pour une approche territoriale des transitions écologiques. Analyse de la transition vers l'agroécologie dans la Biovallée. AgroParisTech, Paris.

Callon, M., 1981. Struggles and negotiations to define what is problematic and what is not, in: The Social Process of Scientific Investigation. Springer, pp. 197-219.

Callon, M., Law, J., 1982. On interests and their transformation: enrolment and counterenrolment. Soc. Stud. Sci. 12, 615-625.

Cardona, A., 2012. L'agriculture à l'épreuve de l'écologisation : éléments pour une sociologie des transitions. Paris, EHESS.

Cowan, R., Gunby, P., 1996. Sprayed to Death: Path Dependence, Lock-in and Pest Control Strategies. Econ. J. 106, 521-542. doi:10.2307/2235561

Darnhofer, I., Sutherland, L. A., Pinto-Correia, T., Sutherland, L., Wilson, G. A. , Zagata, L. et al., 2014. Conceptual insights derived from case studies on 'emerging transitions' in farming. In L. Sutherland, I. Darnhofer, G. Wilson, L Zagata, 2014, Transition pathways towards sustainability in agriculture: case studies from Europe, Hardback., 189-203.

Deverre, C., Lamine, C., 2010. Les systèmes agroalimentaires alternatifs. Une revue de travaux anglophones en sciences sociales. Économie Rurale 57-73.

Diaz, M., Darnhofer, I., Darrot, C., Beuret, J.-E., 2013. Green tides in Brittany: What can we learn about niche-regime interactions? Environ. Innov. Soc. Transit. 8, 62-75.

Dubuisson-Quellier, S., Lamine, C., Le Velly, R., 2011. Citizenship and consumption: Mobilisation in alternative food systems in France. Sociol. Rural. 51, 304-323. 
Elzen, B., van Mierlo, B., Leeuwis, C., 2012. Anchoring of innovations: Assessing Dutch efforts to harvest energy from glasshouses. Environ. Innov. Soc. Transit. 5, 1-18. doi:10.1016/j.eist.2012.10.006

Geels, F., 2002. Technological transitions as evolutionary reconfiguration processes: a multilevel perspective and a case-study. Res. POLICY 31, 1257-1274. doi:10.1016/S00487333(02)00062-8

Geels, F.W., 2011. The multi-level perspective on sustainability transitions: Responses to seven criticisms. Environ. Innov. Soc. Transit. 1, 24-40. doi:10.1016/j.eist.2011.02.002

Geels, F.W., Schot, J., 2007. Typology of sociotechnical transition pathways. Res. Policy 36, 399-417. doi:10.1016/j.respol.2007.01.003

Genus, A., Coles, A.-M., 2008. Rethinking the multi-level perspective of technological transitions. Res. Policy 37, 1436-1445. doi:10.1016/j.respol.2008.05.006

Goodman, D., DuPuis, E.M., Goodman, M.K., 2011. Alternative Food Networks: Knowledge, Practice, and Politics. Routledge.

Ingram, J., Maye, D., Kirwan, J., Curry, N., Kubinakova, K., 2015. Interactions between Niche and Regime: An Analysis of Learning and Innovation Networks for Sustainable Agriculture across Europe. The Journal of Agricultural Education and Extension 21:1, 55-71.

Kemp, R., Schot, J., Hoogma, R., 1998. Regime shifts to sustainability through processes of niche formation: The approach of strategic niche management. Technol. Anal. Strateg. Manag. 10, 175-198. doi:10.1080/09537329808524310 
Lamine, C., Renting, H., Rossi, A., Wiskerke, J.H., Brunori, G., 2012. Agri-food systems and territorial development: innovations, new dynamics and changing governance mechanisms, in: Farming Systems Research into the 21st Century: The New Dynamic. Springer, pp. 229256.

Markard, J. and Truffer, B., 2008. Technological innovation systems and the multi-level perspective: Towards an integrated framework. Research policy 37:4, 596-615.

Rip, A., Kemp, R., 1998. Technological Change. In: Rayner S., Malone EL (eds). Battelle press.

Smith, A., 2006. Green niches in sustainable development: the case of organic food in the United Kingdom. Environment \& Planning C: Government \& Policy 24, 439-358

Smith, A., 2007. Translating sustainabilities between green niches and socio-technical regimes. Technol. Anal. Strateg. Manag. 19, 427-450.

Stassart, P.M., Jamar, D., 2009. Agriculture biologique et verrouillage des systèmes de connaissances: Conventionalisation des filières agroalimentaire bio. Carrefours Innov. Agron. $4,313-328$.

Tregear, A., 2011. Progressing knowledge in alternative and local food networks: critical reflections and a research agenda. J. Rural Stud. 27, 419-430.

Vanloqueren, G., Baret, P.V., 2008. Why are ecological, low-input, multi-resistant wheat cultivars slow to develop commercially? A Belgian agricultural "lock-in" case study. Ecol. Econ. 66, 436-446. doi:10.1016/j.ecolecon.2007.10.007 
Wiskerke, J.S., Van der Ploeg, J.D., 2004. Seeds of Transition: Essays in Novelty Production, Niches and Regimes in Agriculture. Uitgeverij Van Gorcum. 